Revue d'histoire de l'Amérique française

REVUE D.HISTOIRE DE L'AMÉRIQUE FRANÇAISE

SAMSON, Roch, Pêcheurs et marchands de la baie de Gaspé au XIXe siècle. Ottawa, Direction des lieux et des parcs historiques nationaux, Parcs Canada, 1984. 148 p. 6,25 \$.

\title{
Mario Lalancette
}

Volume 39, numéro 4, printemps 1986

URI : https://id.erudit.org/iderudit/304404ar

DOI : https://doi.org/10.7202/304404ar

Aller au sommaire du numéro

Éditeur(s)

Institut d'histoire de l'Amérique française

ISSN

0035-2357 (imprimé)

1492-1383 (numérique)

Découvrir la revue

Citer ce compte rendu

Lalancette, M. (1986). Compte rendu de [SAMSON, Roch, Pêcheurs et marchands

de la baie de Gaspé au XIXe siècle. Ottawa, Direction des lieux et des parcs

historiques nationaux, Parcs Canada, 1984. 148 p. 6,25 \$.] Revue d'histoire de

l'Amérique française, 39(4), 595-597. https://doi.org/10.7202/304404ar d'utilisation que vous pouvez consulter en ligne.

https://apropos.erudit.org/fr/usagers/politique-dutilisation/ 
SAMSON, Roch, Pêcheurs et marchands de la baie de Gaspé au XIXe siècle. Ottawa, Direction des lieux et des parcs historiques nationaux, Parcs Canada, 1984. 148 p. $6,25 \$$

Plusieurs livres et articles ont été récemment publiés sur l'histoire de la Gaspésie (Aliette Geistdoerfer, Jules Bélanger et coll., André Lepage, David Lee, Rose-Mary Omer, etc). La plupart de ces ouvrages s'intéressent à divers degrés au fameux «système» de crédit, mieux connu sous le nom de «Truck System», qui caractérise les rapports marchands/pêcheurs dans la région du golfe Saint-Laurent jusqu'au début du 20e siècle. En 1981, l'anthropologue Roch Samson soumettait à Parcs Canada une étude sur le même sujet devant servir à l'interprétation historique de la vie sociale et économique des pêcheurs et marchands qui ont vécu au $19 \mathrm{e}$ siècle dans les limites de ce qui constitue à présent, le parc national de Forillon.

Pour réaliser cette étude, Samson a su tirer profit d'une documentation exceptionnelle, soit les livres de compte et la correspondance de la Compagnie William Hyman and Sons, active à Grande-Grave de 1845 à 1967. Le tout a été 
complété par une recherche exhaustive sur les transactions foncières de divers marchands gaspésiens pour la seconde moitié du 19e siècle. C'est donc à partir d'un cas concret que Samson tente, dans une perspective d'anthropologie économique, de faire l'analyse des fondements et du fonctionnement du système commercial établi en Gaspésie. En s'appuyant sur le matérialisme historique et sur les plus récents acquis historiographiques, il souhaite démontrer comment l'organisation de la production de la morue séchée a façonné l'ensemble social gaspésien (p. 9).

L'ouvrage retient d'abord l'attention par la qualité de sa structure. Une brève introduction historiographique souligne l'apport essentiel des travaux de Innis. L'explication du sous-développement de la Gaspésie par un «argument de mentalité laissant croire à une population enfermée dans la coutume et la tradition» (p. 12), tel que l'ont avancée Fernand Ouellet, Jean Hamelin et Yves Roby, est clairement remise en cause. Le premier chapitre, trop succinct, retrace l'histoire de la maison Hyman et tente d'en évaluer la position au sein du monde marchand gaspésien.

L'essentiel de l'ouvrage tient cependant dans les trois chapitres suivants. D'abord, Samson décrit de façon concluante les aspects techniques, la force de travail et les unités de production, en insistant sur les contraintes d'ordre écologique, technologique, démographique et autres, qui entrent en jeu dans la production de la morue séchée. L'auteur prend soin de bien faire ressortir la hiérarchie qui existe au sein du groupe des pêcheurs pour détruire le vieux mythe d'une société homogène constituée de pauvres pêcheurs, tous endettés et esclaves des marchands anglo-normands (William Hyman fait alors figure d'exception en Gaspésie, puisqu'il était d'origine russe et de religion juive). L'analyse des rapports sociaux issus du procès de production de la morue séchée, objet du troisième chapitre, permet à l'auteur d'insister sur la diversité possible des rapports existant entre les marchands et leurs différents clients. Enfin, la dernière partie de l'ouvrage est consacrée à l'étude de l'endettement des pêcheurs, phénomène que Samson considère, en définitive, comme le mécanisme essentiel du processus de reproduction du système marchand gaspésien. Toutefois, vu la nature de ses sources, l'auteur a mis l'accent sur l'analyse des facteurs généraux de l'endettement et néglige sciemment les facteurs de variation individuels, tels que le cycle familial, l'état de la propriété foncière, etc.

Pour Samson, c'est le fait que le procès de circulation des marchandises soit accompagné d'une très forte circulation des producteurs qui explique l'implantation et le maintien du système de crédit caractérisant les rapports marchands/pêcheurs en Gaspésie au 19e siècle. Il fallait dans un premier temps attirer des producteurs dans la région et par la suite s'assurer leur fidèle clientèle. L'endettement, réalisé de diverses façons, constitue la meilleure garantie de cette fidélité et devient un élément fondamental du processus de rentabilisation de la participation marchande à la production et à la commercialisation de la morue séchée gaspésienne. Malheureusement, ni la mobilité générale de la population ni la circulation des clients entre les divers marchands n'ont fait ici l'objet d'une étude poussée vu la nature des sources privilégiées. D'ailleurs, l'auteur reconnaît lui-même les limites de son enquête et sa perplexité face à la réalisation et à la persistance du contrôle marchand (p. 77 et 111). 
Ce livre, bien documenté, contribuera certainement au renouvellement de l'image de l'univers des pêcheurs de la Gaspésie du 19e siècle. L'auteur parvient à bien mettre en lumière certaines spécificités des rapports marchands/ pêcheurs au sein de la société gaspésienne à travers son analyse précise du procès de production de la morue séchée et une présentation plus sommaire du procès de circulation des marchandises (approvisionnement des producteurs et écoulement des productions sous le contrôle monopoliste des marchands). Toutefois, si une telle démarche est fondamentale, il faudra explorer nombre d'autres réalités, d'ordre économique, social, politique et idéologique, et déterminer leur impact sur les rapports sociaux, avant de pouvoir tracer un schéma explicatif global satisfaisant de la société gaspésienne du 19e siècle.

Considérant la qualité de l'analyse du processus de production de la morue séchée et l'abondance et la pertinence des illustrations, graphiques et appendices, on comprend aisément pourquoi cet ouvrage s'est mérité le prix Michel Brunet 1985 de l'Institut d'histoire de l'Amérique française.

Département d' histoire

Université McGill

MARIO LALANCETTE 